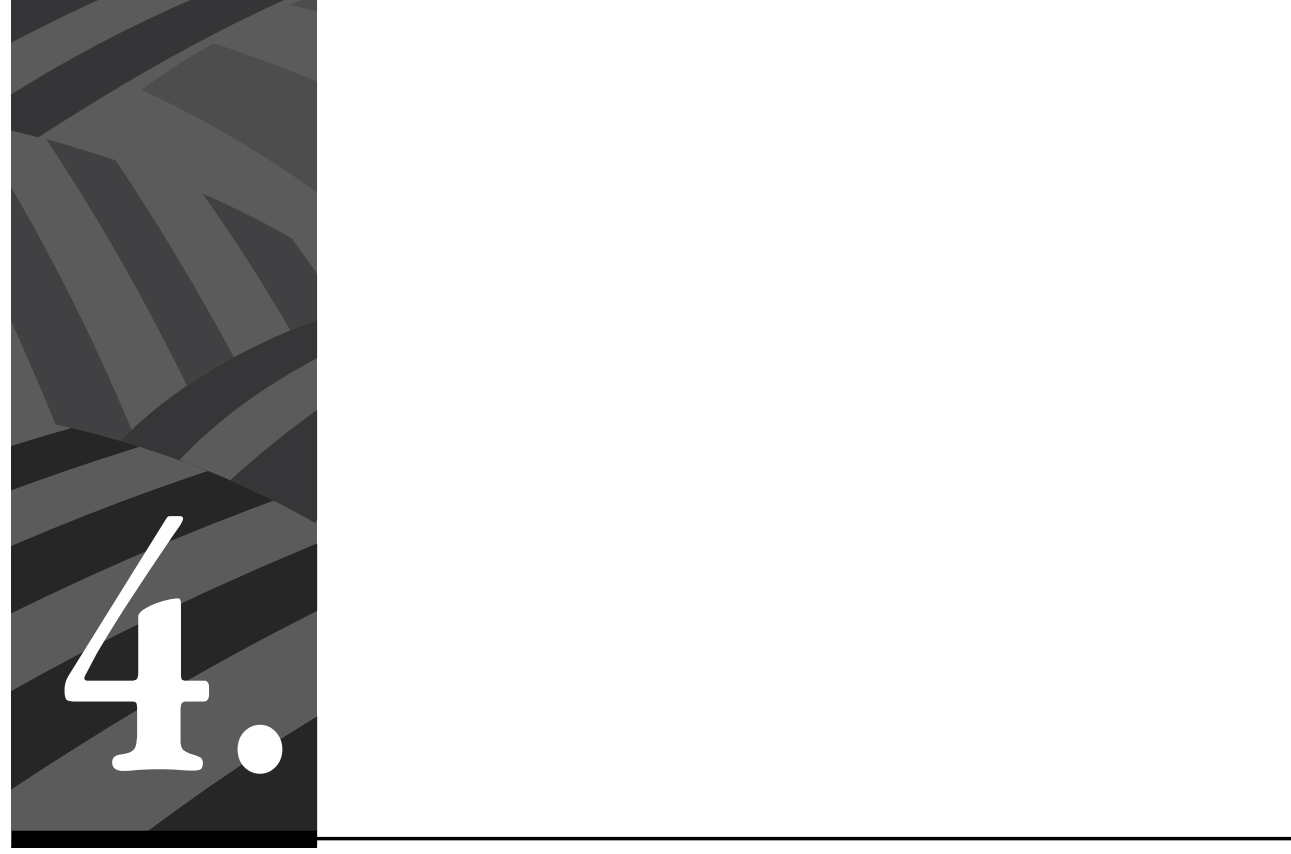

La Plata, resistencia etno-eco-social. Movilización, territorios y Estado en el Pacífico colombiano 


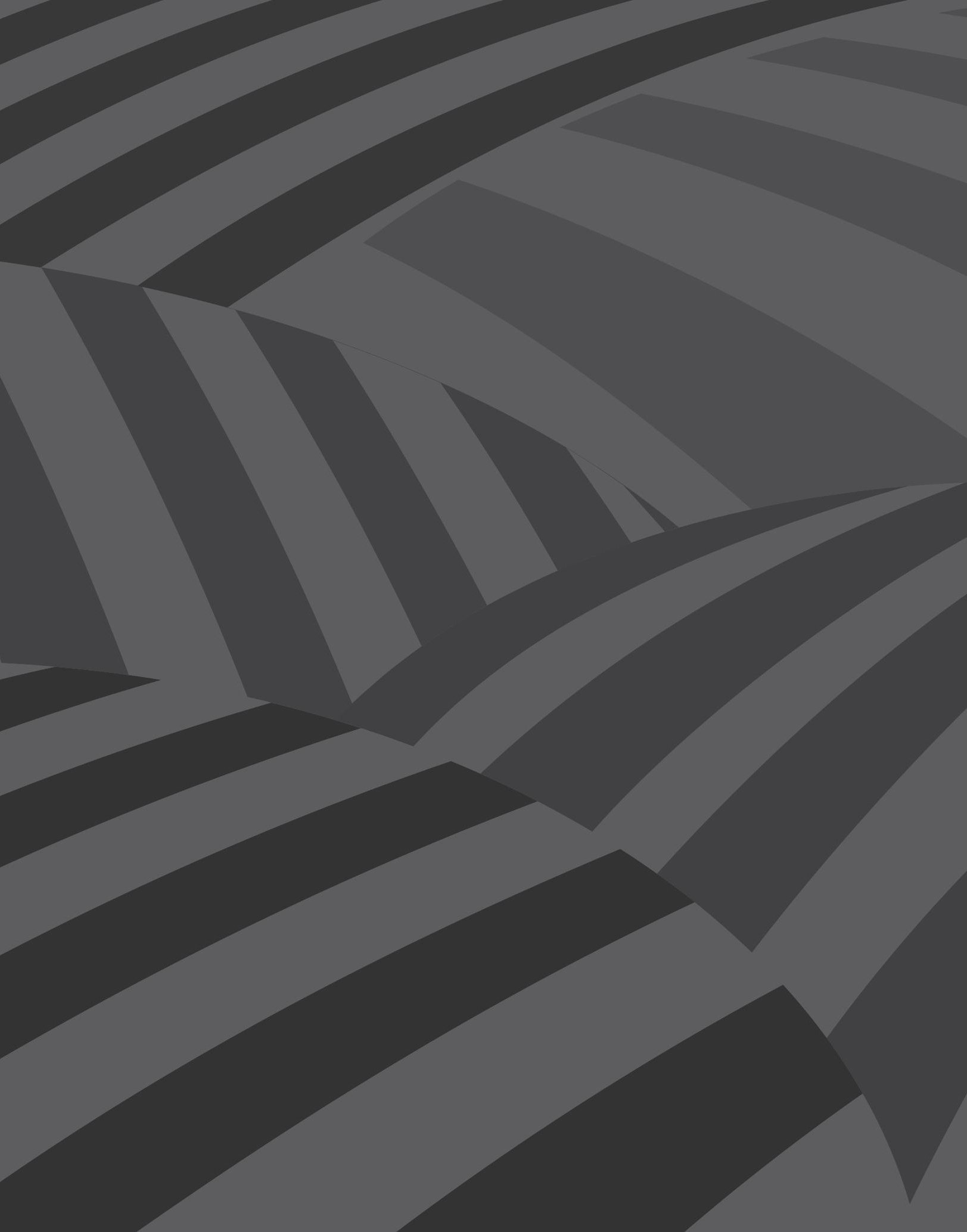




\section{La Plata, resistencia etno-eco-social. Movilización, territorios y Estado en el Pacífico colombiano}

Por Luis Fernando Barón*, Scarlet Sotomayor Tacuri** y la participación de miembros del Consejo Comunitario de la Plata**

Resumen $^{1}$ : Este artículo presenta una trayectoria de los procesos organizativos y de movilización social de La Plata, comunidad negra de Buenaventura, Colombia, que ha sobrevivido y resistido, gracias a la implementación de formas de organización y de interacción con instituciones locales, nacionales e internacionales. Más allá de crear órdenes sociales o políticos distintos, las movilizaciones sociales en La Plata evidencian una lucha por el reconocimiento y la articulación de sus diferencias territoriales y étnicas al proyecto de Estado-nación, al tiempo que contribuyen a la reconfiguración del mismo y a la reconstrucción de poderes locales. El trabajo es resultado de un proceso participativo de investigación y diálogo de saberes adelantado por más de tres años con el Consejo Comunitario de La Plata.

Palabras clave: Colombia, Pacífico, movimientos sociales, territorios, desarrollo.

* Profesor e investigador de la Universidad Icesi, con estudios en Comunicación y Antropología y Ph. D. en Ciencias de la Información

** Investigadora independiente. Antropóloga de la Universidad Icesi y maestra en Ciencias Sociales con mención en Género y Desarrollo de la Facultad Latinoamericana de Ciencias Sociales

*** Este trabajo es el resultado de la participación de las comunidades del Consejo Comunitario de La Plata y de la Junta del Consejo, especialmente de Ferney Valencia y Saúl Valencia. A todos ellos, muchas gracias por la confianza y la generosidad con que nos han recibido, por acogernos en sus territorios y hogares y por los conocimientos e historias que han compartido con nosotros. También agradecemos los trabajos de campo y los análisis de los estudiantes de la Universidad Icesi: María Camila Beltrán, Marie Thorn, Alexandra Hau, Luis Alfredo López, Francisco Yepes y María Isabel Galindo

1 Este texto hace parte del Proyecto de Investigación Territorios, Movilización y Derechos, de la Universidad Icesi, e incluye aprendizajes e información de proyectos previos y en curso como el desarrollado con las Facultades de Ciencias de la Salud, de Administración y Economía en El Guabal, Guachené Cauca, y el Proyecto Interinstitucional Modelo de atención primaria en salud diferencial para municipios con alta dispersión rural del litoral Pacífico, apoyado por Colciencias 


\section{Territories, Development and Mobilization. La Plata an Example of Eco-etno-social Resistance}

Abstract: This paper presents a journey through the organizational and mobilization stories of La Plata, a black community in the Colombian Pacific. This community has survived, has resisted, thanks to both forms of organization and interaction with institutions at local, national and international level. Social mobilizations in La Plata, reveal not a struggle for seeking or creating new orders, but a fight for their recognition and articulation to the nation-state, while these processes not only transform the same State, but also rebuild local powers. This work is the result of more than three years of a participatory research process and a dialogue of knowledge with the Communitarian Council of La Plata.

Keywords: Colombia, pacific region, social movements, territories, development.

Cómo citar este artículo: Barón, Luis Fernando y Sotomayor Tacuri, Scarlet (2019). La Plata, resistencia etno-eco-social. Movilización, territorios y Estado en el Pacífico colombiano. Revista Controversia, 213, 147-189.

Fecha de recepción: 22 de febrero de 2019

Fecha de aprobación: 13 de junio de 2019

\section{Introducción}

El mar es

fuente de energía alimentaria

vitalidad en lo ancestral hogar y banco alimenticio $y$ dependencia astral.

Fragmento de un poema de Salomón Molano, La Plata, 2016

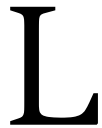
os relatos transmitidos oralmente en Bahía Málaga dicen que desde mediados del siglo XIX sus tierras ya eran habitadas por comunidades negras que vivían de los recursos que les ofrecían la tierra, el bosque y el mar: la bahía les brindó alimentos, los árboles les proveyeron de maderas para construir cabañas y canoas para transportarse, y la pesca, la caza, la recolección de mariscos y la agricultura eran sus principales fuentes de autosustento, heredadas de generación 
en generación hasta convertirse en legado cultural para sus pobladores. Uno de sus habitantes agrega que desde ese tiempo se «iniciaron procesos de organización con el fin de establecer normas de convivencia, de identificar, seleccionar y dividir las tareas que se requerían para subsistir como comunidad».

Estudiosos del litoral Pacífico colombiano como Escobar y Pedroza (1996), Restrepo y Leal (2003) y Hoffmann (2003) sostienen que los territorios de la zona centro y norte del Pacífico eran habitados por comunidades emberas y waunanas; a partir del siglo XVI, llegaron hasta ahí colonos españoles atraídos por la explotación de oro, quienes traían consigo negros esclavizados de África (Wagbou, Vargas y Carabalí, 2012). Según Aprile-Gniset (2002), los puertos de Buenaventura, Guapi y Tumaco surgieron a fines del siglo XVII y alcanzaron su consolidación a mediados del XVIII "como cortos rancheríos de cimarrones costeros y de libres de todos los colores» (p. 22).

Hoffmann (2003) y Asher (2016) agregan que la emancipación de los esclavos a mediados del siglo XIX y el detrimento de la actividad minera en la zona a finales del mismo siglo, así como las migraciones de población negra desde el interior del país y los piedemontes mineros, posibilitaron formas de organización social constituidas por pequeños poblados distribuidos a lo largo de los ríos y costas del Pacífico. De acuerdo con Hoffman, tres rasgos han caracterizado a los pobladores de esta región: las redes de parentesco en la construcción de veredas y en la estructura de la vida local, la importancia de los ríos como lugares de reconocimiento social y político y la combinación de actividades económicas con ambiguas relaciones de inserción/dependencia de la producción campesina frente a los mercados nacionales e internacionales.

Según Serje (2005), las luchas por la formación de la República del siglo XIX incluyeron la definición de los límites del país y con ella la demarcación de zonas integradas y aquellas consideradas como baldías².

2 En general, se consideraba que estas tierras baldías «escondían enormes tesoros y oportunidades e incluían riquezas minerales y vegetales» (Serje, 2005, p. 4). 
Esto contribuyó al desarrollo de fronteras físicas y simbólicas entre los «centros y las periferias» del país y de procesos diferenciales de inclusión y exclusión de comunidades locales en el naciente Estado-nación. Para el autor, dichos procesos se fundan en nociones coloniales preconcebidas, firmemente arraigadas en el «sentido común» de las personas, y reproducen lógicas geopolíticas marcadas, que ponen en el centro la riqueza de la tierra y el territorio de las comunidades indígenas, negras y afro.

En el siglo xx, la construcción del Ferrocarril del Pacífico asociada con el impulso y el crecimiento de la producción y comercialización de café y azúcar ${ }^{3}$ fueron determinantes para los vínculos de Buenaventura con la región suroccidental y con la nación. Asimismo, van a tener una fuerte incidencia en sus procesos de poblamiento hasta los tiempos contemporáneos, pues el puerto ha sido centro de atracción de inversionistas y colonos nacionales y extranjeros (Ó Loingsigh, 2013).

De manera similar tuvieron significativas implicaciones las políticas educativas y los procesos de evangelización de la Iglesia católica en la región ${ }^{4}$, así como las políticas estatales de conservación forestal ${ }^{5}$ que desde mediados del siglo pasado tuvieron efectos en las concepciones, la apropiación y los usos de bosques y de tierras consideradas como baldías ${ }^{6}$.

Escobar (2008) sostiene que el modelo de apropiación territorial en el Pacífico se empezó a transformar después de los años cincuenta, producto de la colonización creciente, el desarrollismo, los cambios tecnológicos en la minería, la pesca y la extracción de madera y de grandes

3 Desde los inicios de los ingenios azucareros del valle del río Cauca, Buenaventura ha estado significativamente vinculada con la industria del azúcar. Para ampliar la información, véase: Potes, Burbano y Rodríguez (2013) y Kafarov, Ojeda y Sánchez (2006).

4 Para ampliar la información, véase: Hoffmann (2003), Escobar (2008) y Asher (2016).

5 Véase la ley de Zonas de Reserva forestal, que incluye la del Pacífico, Ley 2 del 16 de diciembre 1959, que responde a la clasificación del Decreto Legislativo 2278 de 1953 y establece espacios de desarrollo de la economía forestal y la protección de suelos, aguas y vida silvestre.

6 Para ampliar la información, véase: Centro Nacional de Memoria Histórica (2015). 
concesiones de tierra a compañías extranjeras. En consecuencia, «la frontera finalmente se cerró» (pp. 65-66).

Pero quizá el mayor impacto en los procesos de poblamiento y desarrollo territorial en la región desde finales del siglo pasado tuvo origen en el reconocimiento étnico negro y afrocolombiano en la región Pacífica desde los años ochenta y en los proyectos organizativos de comunidades negras y afrocolombianas. Posteriormente, estos lograron la inclusión del artículo transitorio 55 en la Constitución Nacional de 1991 y abrieron las puertas a la promulgación y desarrollo de la Ley 70 de 1993, que ha permitido el otorgamiento de más de 6 millones de hectáreas en territorios colectivos a comunidades negras en el Pacífico ${ }^{7}$.

Este rápido recorrido por los procesos de poblamiento en la región sirve para ubicar el Consejo Comunitario de La Plata (СCP), que hace parte del municipio de Buenaventura, principal puerto del Pacífico colombiano que hoy maneja más del $50 \%$ del total de importaciones y exportaciones del país y que para 2017 transportó más de 22 millones de carga de comercio exterior (El País, 29 de enero de 2018). Está ubicado en un estuario rico en recursos naturales y ancestrales rodeado de otros cuatro consejos: Juanchaco, Ladrilleros, La Barra y Puerto España. El CCP de La Plata tiene 36397 hectáreas tituladas y está compuesto por cuatro veredas: La Sierpe, Miramar, Mangaña y La Plata.

Este Consejo, como sucede con otras comunidades del litoral Pacífico, ha logrado sobrevivir, superar diferentes conflictos y disputas sociales y mantener el orden de sus territorios, a pesar de las formas precarias y parciales de reconocimiento e integración con el Estado-nación. Lo anterior se evidencia tanto en los planes y en la instalación de instituciones débiles de educación, salud, cultura y desarrollo, impulsados generalmente desde afuera por instituciones estatales y oNG nacionales e internacionales, así como en su articulación a redes políticas de carácter

7 Para ampliar la información sobre las cifras, véase: Domínguez (2017) o Cardona (2017). 
clientelista o de iglesias y congregaciones religiosas. Estos vínculos también se han producido mediante su integración a cadenas económicas (mayoritariamente extractivas), de madera, minería, pesca y recolección de moluscos, o por medio de actos institucionales de regularización y titulación de tierras, con la presencia, temporal o permanente, de las fuerzas armadas, legales e ilegales (Asher, 2016; Cinep/ Programa por la Paz, 2016; Defensoría del Pueblo, 2016).

El Consejo de La Plata y varias comunidades del Pacífico también han tenido que enfrentar representaciones construidas sobre esta región: se piensa en este como un territorio de inagotables riquezas naturales y culturales, de difíciles condiciones de habitación, que solo son resistidas por comunidades indígenas o negras, incluso como zonas no habitadas, y como una región estratégica de conexión económica con el Pacífico norteamericano y latinoamericano y, más recientemente, con el del mundo global, representado por las economías emergentes de países asiáticos $^{8}$ (CNMH, 2015; Escobar, 2008; Leal y Restrepo, 1994). Paradójicamente, el diseño e implementación de megaproyectos de desarrollo (portuarios, petroleros, minero-extractivos, agroindustriales y de comunicaciones) y el mismo conflicto político armado son los hechos que más visibilidad y dinamismo han otorgado a los procesos de organización y movilización social en La Plata. A esto se suman los movimientos y protestas sociales ${ }^{9}$ por la definición y el ejercicio de los derechos étnicos, de salud, de trabajo y educación y a la vida misma ${ }^{10}$.

8 Por ejemplo, en 2011, el Banco Mundial mostraba que la Cuenca del Pacífico contaba con más de 2700 millones de habitantes, con el $55 \%$ del PIB mundial y con una demanda de productos de aproximadamente US $\$ 7$ billones.

9 Para los efectos de este trabajo, entendemos las protestas sociales como formas de expresión política que buscan cambios sociales o políticos, e influir en el conocimiento, las actitudes y los comportamientos públicos o las políticas de una organización o institución.

10 En 2017, el cc de La Plata y la Universidad Icesi adelantaron un Censo que incluye información más detallada sobre los asuntos mencionados. 
Como resultado de una concertación entre el Consejo Comunitario de La Plata e investigadores de la Universidad Icesi, de Cali, diseñamos y trabajamos en un proyecto de investigación participativa por más de tres años, con el propósito de conocer los procesos organizativos y de movilización en su territorio, así como los conflictos sociopolíticos, territoriales y ambientales que esta comunidad ha enfrentado con instituciones de carácter local, nacional y global y en las mismas comunidades y sus organizaciones. La metodología combina la revisión bibliográfica y de archivos con estrategias cualitativas como la etnografía, las cartografías sociales, las entrevistas en profundidad, los talleres y las observaciones participantes, con métodos cuantitativos como las encuestas y un censo.

Los resultados de este caminar compartido están organizados en tres apartados centrales. El primer apartado presenta una trayectoria de los procesos de movilización en la región y el segundo identifica cuatro episodios $^{11}$ de movilización social durante las últimas cuatro décadas en La Plata. El primero de estos episodios está relacionado con la planeación y construcción de la Base Naval en Bahía Málaga; el segundo con las disputas territoriales con agentes como la Universidad del Valle, las comunidades indígenas y afros y los actores armados; el tercero con la construcción de un puerto de aguas profundas en Bahía Málaga y el cuarto muestra acciones centradas en actividades económicas y de generación de ingresos, vinculadas con la pesca, la caza y el uso de los bosques y la madera. Finalmente, en el tercer apartado, el texto plantea algunas discusiones y conclusiones que muestran que los procesos organizativos y de movilización en La Plata representan reclamos de

11 Los episodios son comprendidos aquí desde las perspectivas de McAdam, Tarrow y Tilly (2001), quienes proponen entenderlos como unidades de observación, para entender mejor las múltiples y móviles relaciones entre oportunidades políticas, estructuras y marcos de movilización. Es decir, como momentos decisivos en las movilizaciones sociales que son dinámicos y articulados. 
reconocimiento y co-construcción ${ }^{12}$ del Estado-nación, que también se juegan en disputas internas en las organizaciones y movimientos negros y afros del Pacífico y en el mismo cCP. ${ }^{13}$

\section{Trayectorias de organización y movilización social en el Pacífico y Buenaventura}

En el Pacífico hay una rica historia de movilizaciones que van desde las resistencias al modelo esclavista, las luchas sindicales y las exigencias por la tierra, hasta la protección de territorios ancestrales y la reivindicación de identidades. Después de los cimarronajes y la automanumisión ${ }^{14}$, se abolió la esclavitud en Colombia en 1852; sin embargo, en la zona de Buenaventura, fue hasta inicios de los años cincuenta que se produjeron movilizaciones con el fin de denunciar la discriminación histórica de los negros ${ }^{15}$.

Durante estos años, los cambios en los procesos de poblamiento en el Pacífico abrieron las posibilidades de extracción de los recursos por agentes externos y la creciente presencia de misioneros, agencias del Estado y de diferentes proyectos de desarrollo en la región (Escobar, 2008). Hoffmann (2003), Escobar (2008) y Asher (2016) coinciden en la importancia de las organizaciones católicas en los procesos organizativos y de movilización y en el desarrollo de estrategias para el uso de los recursos naturales y de nuevas formas de propiedad de la tierra.

12 Fortunati, Pertierra y Vincent (2012) han propuesto el concepto de co-construcción, que asume cada colectividad como un sistema dinámico que se encuentra y choca con otras culturas, pero al hacerlo se enriquece y se transforma.

13 Para ampliar la información, véase: Domínguez (2017).

14 Los primeros referidos a huida individual y colectiva de minas y plantaciones para formar sociedades organizadas y la otra al ahorro que hacían los esclavos para comprar su libertad.

15 Para ampliar la información, véase: Wade (1994), Oslender (1999) y Arocha (1998). 
En los años sesenta, la creación de la empresa pública Puertos de Colombia (Colpuertos) en Buenaventura incentivó los procesos de asociación laboral y la construcción de una fuerte organización sindical, que fortaleció el surgimiento de élites políticas locales y se articuló a la formación de la Federación Nacional de Trabajadores Portuarios, una de las más importantes de Colombia en los años setenta. De este modo, «se consolidó una clase media que empezó a ocupar cargos políticos en la administración local y cargos directivos en la empresa pública (Colpuertos)» (Centro Nacional de Memoria Histórica, 2015, p. 47).

A mediados de los años setenta, empiezan a confluir las luchas económicas, sociales y políticas en la región, lo que también evidencian la mezcla de demandas de carácter étnico con otras de defensa de sus territorios (Walsh, León y Restrepo, 2005). En 1976, la implementación de un Plan Regulador de tierras en Bahía Málaga desencadenó el enfrentamiento entre los colonos de la región y la Corporación de Turismo del Valle (Cortuvalle) que buscaba vender públicamente 33,4 hectáreas. Para Sánchez (2011), el conflicto ponía en evidencia el desconocimiento de los resultados de un primer censo practicado por el Instituto Agustín Codazzi dos años antes, que ya mostraba 300 posesiones en las diferentes islas de Bahía Málaga.

En los años ochenta surgen organizaciones con explícitos reclamos por los derechos de las comunidades negras y afros sobre sus tierras y territorios como la Asociación Campesina Integral del Atrato (ACIA ${ }^{16}$ ) o la Asociación Campesina del San Juan (Acadesan). Su principal objetivo era unir y capacitar a las poblaciones negras a fin de que pudieran superar los conflictos territoriales con los indígenas wounaan y enfrentar el Plan Pacífico, que incluía exploraciones petroleras, la base militar y proyectos como el polieducto de Bahía Málaga, las hidroeléctricas de Calima, la canalización de esteros y los puertos de aguas profundas, entre otros.

16 Para mayor información, véase Asher (2016) y De la Torre (2002). 
El surgimiento y desarrollo de estas organizaciones hacen parte de los procesos y trabajos de etnización negra y afrocolombiana en el Pacífico colombiano. Según lo exponen diferentes analistas como Asher (2016), Hoffman (2003 y 2007), Restrepo (2001 y 2011) y Escobar (2008), estas tienen vínculos con los movimientos y discusiones políticas, culturales y académicas de orden nacional e internacional, que incluyen aspectos tan variados como: los primeros estudios de y sobre negros en Colombia; el accionar de Comunidades Eclesiales de Base inspiradas en la Teología de la Liberación; los movimientos sociales, culturales e intelectuales de derechos civiles en los Estados Unidos; los avances en los pactos mundiales de derechos humanos y derecho internacional humanitario; el conflicto político armado y las oleadas globales de asuntos como el multiculturalismo, las políticas de la diferencia y la diversidad e incluso los estudios regionales, de memoria, de espacio y territorio, entre otros ${ }^{17}$.

Estos asuntos alimentaron los movimientos negros y afro en Colombia, los cuales hacían parte de los nuevos movimientos sociales que, según Escobar y Álvarez (1992), a principios de los años noventa encarnaban la riqueza y complejidad de los procesos de movilización social en América Latina. Para los autores, de estas acciones colectivas destaca la capacidad de ejercer en diferentes regímenes políticos, así como su énfasis en la creatividad política y simbólica; no obstante, critican que el enfoque cultural de los nuevos movimientos resultaba limitado en aquellos contextos en que los cambios sociales se mostraban como necesidades apremiantes y las dinámicas económicas y políticas estaban profundamente articuladas con los fenómenos culturales ${ }^{18}$.

Más recientemente, Calderón (2012) demuestra que las movilizaciones sociales en América Latina hacen parte constitutiva de sus procesos

17 Para ampliar la información sobre memorias, territorios y mundo global, véase: Said (2000) o Sassen (2000).

18 Para ampliar la información, véase: Ruggiero y Montagna (2008). 
políticos y de las prácticas democráticas mismas. Señala, además, que los conflictos del continente comparten rasgos comunes: a) la existencia de estructuras de poder muy concentradas y una desigualdad crónica, b) un alto número e intensidad, c) la tendencia a expresarse más en medios masivos y sociales de comunicación y d) la amplia participación ciudadana, que contrasta con la debilidad estatal y con la insuficiencia de instituciones para gestionar conflictos dentro de los marcos democráticos.

Los autores también identifican tres campos prioritarios de conflictos en el continente: mientras las luchas económicas buscan una mejor calidad de vida y propenden por mayor eficacia y legitimidad del Estado, los conflictos culturales buscan cambiar los modos de vida; en este sentido, son conflictos estratégicos. Un ejemplo claro de esto fueron los hechos previos a la Constitución de 1991, puesto que se venían gestando expresiones organizativas étnicas aisladas unas de otras, con diversas posturas políticas, que dieron lugar a la Coordinadora Nacional de Comunidades Negras ( $\mathrm{CNCN}$ ), cuyas relaciones con partidos tradicionales y de izquierda posibilitaron su separación y la construcción, una vez emitido el Artículo Transitorio 55, mencionado antes (Grueso, Rosero y Escobar, 1997, pp. 48-50).

Después de la emisión de la Ley 70 de $1993^{19}$, se inicia un proceso de consolidación del movimiento por la etnicidad negra, definida principalmente en términos de culturas propias e historias comunes, y de compresión de los territorios como una construcción política para la defensa de sus derechos y nociones de desarrollo autónomas (Domínguez, 2017; Escobar, 2008; Restrepo, 2001).

19 Con la cual se desarrolló el artículo Transitorio 55. Tenía por objeto reconocer a las comunidades negras del Pacífico el derecho a la propiedad colectiva de las tierras que han ocupado. Además, buscaba implementar mecanismos para la protección de la identidad cultural y de los derechos de las comunidades negras de Colombia como grupo étnico, y el fomento de su desarrollo económico y social, con el fin de garantizar condiciones reales de igualdad de oportunidades frente al resto de la sociedad colombiana. 
A partir de la segunda mitad de los años noventa, los procesos organizativos de las comunidades negras y afrodescendientes en Buenaventura inician la exigibilidad política para la titulación de sus territorios que, a pesar de tener la demarcación de 600000 hectáreas para las comunidades indígenas y negras del Pacífico, desde 1987, no estaban legalmente titulados bajo el reconocimiento de sus posesiones históricas (Escobar, 2008, p. 68). Para Escobar (2010), estos procesos aportaron a la concepción del territorio como espacio de apropiación de los ecosistemas por unas comunidades dadas, mientras que la noción del Pacífico como territorio-región de grupos étnicos es concebida con mayor claridad como una construcción política para la defensa de los mismos territorios.

Este tipo de procesos coinciden con los análisis de Zibechi (2012), que identifican la territorialización como una de las principales características de los movimientos más representativos en América Latina. Así mismo, esta incluye la recuperación o aseguramiento de espacios mediante largas luchas, abiertas o clandestinas, que han derivado en la relocalización de sectores populares y comunidades étnicas, lo que ha generado nuevos territorios en ciudades o en áreas rurales. Desde sus territorios los nuevos actores han consolidado proyectos a largo plazo caracterizados por su capacidad para producir y reproducir la vida y establecer alianzas con otros sectores populares y de la clase media.

De acuerdo con Domínguez (2017), a 2010 los procesos de titulación de tierras (adjudicadas o en curso) cubrían casi la totalidad de las zonas libres o baldías del municipio de Buenaventura. Para la autora, estos procesos no solo han contribuido a la generación de nuevas formas de organización territorial, sino también a la creación de otros canales y maneras de interacción y mediación con instituciones del Estado nacional, de los que también hacen parte líderes de estas organizaciones. Los procesos de definición y titulación colectiva de las comunidades negras enfatizaron «las prácticas colectivas de las comunidades, refiriéndose a los ecosistemas estratégicos, los recursos genéticos y la biodiversidad existente en el Pacífico, poniendo como precedente que la Nación les 
reconocía a las comunidades el saber ancestral para cuidarlos» (pp. 179-180).

Los aportes de Escobar y Álvarez (1992), Calderón (2012) y Zibechi (2012) nos ayudan a reconocer los vínculos que hay en los movimientos sociales contemporáneos entre asuntos culturales y otros de carácter político, económico y tecnológico, y su articulación con las luchas por el cambio social y las pugnas democráticas en contextos locales. También nos permiten analizar las relaciones entre agentes, contextos y repertorios (institucionales y no institucionales), con asuntos de orden material, cognitivo y cultural. Con estos referentes proponemos brindar unos primeros insumos que contribuyan a las discusiones contemporáneas sobre las relaciones entre los procesos organizativos y de movilización social con fenómenos como la territorialización y las formaciones del Estado-nación.

En ese orden de ideas, las trayectorias de organización y movilización de La Plata evidencian formas de resistencia permanentes, pacíficas y activas que interpelan órdenes locales, regionales y nacionales ${ }^{20}$. En este caso, tienen un carácter etno-eco-social, porque, de forma articulada, han recurrido al reconocimiento colectivo de identidades fundadas en historias y prácticas culturales comunes; apuntan a formas de sobrevivencia y sistemas económicos no extractivos soportados en la búsqueda de relaciones armónicas con la naturaleza y los seres que la habitan; y propenden por formas de organización y de ejercicio del poder basados en la concertación, la solidaridad y la búsqueda del bienestar general.

20 Para ampliar la información sobre las formas de resistencia, véase: Zuluaga y Romero (2007) y García, Guzmán, Aramburo, Rodríguez y Domínguez (2014). 


\section{Movilizaciones sociales en La Plata: para que los territorios no se queden sin comunidades}

Para nosotros el territorio es un todo.

Hemos resistido sin ser conflictivos.

Hemos resistido por años.

Nuestra vida ha sido la resistencia.

Testimonio miembro de Consejo Comunitario de La Plata ${ }^{21}$.

El Proceso de Comunidades Negras (PCN) apoyó la formación de líderes en el ejercicio y desarrollo de los derechos conquistados a través de la Ley 70 y la formación del Consejo Comunitario de La Plata en Bahía Málaga. La solicitud de titulación colectiva fue hecha por Ernesto Valencia al Instituto Colombiano para la Reforma Agraria (Incora). Mediante la Resolución 000047 de 2003 le fue otorgado el título a las comunidades de las veredas de La Plata, La Sierpe, Miramar y Mangaña con una primera cesión de 7713 hectáreas de tierras. Según Escobar (2013), La Plata fue el primero de los cinco consejos de Buenaventura en lograr un título colectivo, cuyo sistema de gobierno incluye un Código de Régimen Interno ${ }^{22}$, un Plan de Administración de los Recursos Naturales y reglas para el Ecoturismo.

Aunque en las conversaciones y actividades cotidianas los pobladores de La Plata se identifican como campesinos, pescadores, concheras y madereros, en los procesos de socialización, formación y organización social y política, el Consejo ha trabajado por el autorreconocimiento como comunidades negras, bajo la consideración de su carácter diferencial, que se fundamenta en un pasado de ajuste y recreación de cosmovisiones, prácticas, sensibilidades y espiritualidades afro en los territorios que ocupan desde hace más de un siglo.

21 Notas del diario de campo de Beltrán (2016) y Barón (2016).

22 Este código sirve para regular la convivencia cultural y el uso, manejo y ocupación del territorio y toda su riqueza natural (Consejo Comunitario de la Ensenada de Málaga, 2005). 
Las visiones de los líderes del ccp han apuntado a una identidad de comunidad negra que busca destacar y profundizar los avances y desarrollos de la Constitución de 1991, en una lógica de diferenciación racial, étnica y territorial que sea reconocida e incorporada no solo por las instituciones del Esta 2002 do, sino por la sociedad. Lo anterior evidencia que las comunidades negras no han sido homogéneas; sus experiencias organizativas son las que dan cuenta de cómo sus luchas se han integrado para lograr autonomía y autodeterminación (Grueso, Rosero y Escobar, 1997, p. 61). En palabras de Zibechi (2012), estos procesos de movilización por el territorio destacan la búsqueda de independencia frente al Estado y los partidos políticos, fundada en la autonomía material, la revalorización de la cultura y la afirmación de la identidad, la formación de intelectuales propios, la transformación del rol de las mujeres y de las relaciones de género, y sus concepciones y relaciones con la naturaleza y el desarrollo.

En las historias y conocimientos que circulan en la comunidad de La Plata, se pueden identificar cuatro episodios que han determinado su situación presente y las perspectivas que vislumbran a futuro. Esos episodios representan expresiones de sus resistencias etno-eco-sociales. Es importante tener en cuenta que, aunque aquí están organizados de manera cronológica, no corresponden a una lógica secuencial y hay múltiples intersecciones y traslapes entre ellos.

\section{Episodio 1: La construcción de la Base Naval}

Los pobladores de La Plata cuentan que en la zona hubo un cuartel del Ejército Nacional mucho antes de la construcción de la conocida Base Naval durante la Guerra de los Mil Días (1899-1901). Relatan que el gobierno central puso la mirada en su territorio cuando necesitó una cárcel de máxima seguridad, que finalmente se construyó en isla Gorgona en el departamento del Cauca. Su territorio les aseguraba las condiciones geográficas para evitar la huida de los reos; así que, en 1940, «la 
iban a montar acá en La Plata» ${ }^{23}$ junto al cuartel, tal como lo mencionó un viejo de la comunidad en un Taller de línea de tiempo en noviembre de 2016.

La resistencia de los habitantes de la zona evitó la construcción de esa cárcel, pero la organización y protestas de la comunidad no pudieron impedir la construcción de la Base Naval ARC Bahía Málaga de la Armada Nacional en 1989, cuyos terrenos fueron destinados en 1944. El gobierno de Belisario Betancur (1982-1986) lo presentó como un proyecto de «propósito nacional» que beneficiaría la «Soberanía, Defensa e Integración Territorial» desde el Pacífico (Armada Nacional, 2011).

Desde ese momento, comienza una relación que puede resultar ambigua: si bien la llegada de la Base afectó significativamente los ecosistemas de la zona y limitó algunas actividades de la producción tradicional (como el uso de madera de mangle, cultivos de pancoger y otros), también generó seguridad dentro de la comunidad - lo que les ayudó a resolver problemas con comunidades vecinas-, dada la presencia de actores armados en sus territorios.

Por una parte, el impacto ambiental de la construcción y puesta en funcionamiento de la Base «fue terrible», porque acabó con miles de peces y corales, lo que afectó el hábitat marino. La construcción de la carretera de acceso desde Buenaventura - 0 , como la llaman sus habitantes, «carretera vía al gallinero»- limitó la extracción de madera, contaminó los ríos y afectó el desplazamiento de especies nativas. Uno de los «tíos» lo explica así:

(...) lo que pasa es que la carretera está sobre la cordillera y la carretera se tiró a este lado de nosotros. Todas estas quebradas, todo nace allá, entonces a lo que venían haciendo todos esos sedimentos, con esos aguaceros, estas lluvias que usted ve aquí, todo eso se nos vino hacia acá. Tuvieron la

23 Se refiere a la imposición de un cierto orden social, cultural y militar en la zona. 
osadía de que, en muchas de esas quebradas hacían los lavados de carros. En esa época, como nadie decía nada, entonces ellos eran dueños de eso. Eso fue lo que generó tanto sufrimiento a la ecología marina. (Taller de línea de tiempo, La Plata, noviembre de 2016)

Por otra parte, con el establecimiento de la Base en la Bahía, los habitantes de la ensenada se sintieron protegidos no solo de la guerrilla de las FARC, que ha tenido presencia en las zonas rurales de Buenaventura desde finales de los años ochenta, y en los noventa conformaría el Frente Urbano Manuel Cepeda Vargas ${ }^{24}$, sino de comunidades foráneas que llegaron a explotar madera de forma ilegal. Otros pobladores cuentan que la Base Naval se convirtió en el apoyo de salud más cercano, al que acudían cuando necesitaban curar una dolencia. Allí tenían los medicamentos y el personal capacitado para atender cualquier emergencia médica, dos de las necesidades más grandes de la comunidad de La Plata. Las siguientes líneas muestran la importancia de la atención en salud prestada por la Base:

[Los aserradores] también hablaron de las dificultades que se pasan en el monte, como las terribles picaduras de culebra. Incluso uno de los hombres contó que hacía unos meses le habían salvado la vida en la Base Naval porque recordó cortar un trozo del animal que lo mordió, y ello permitió que los médicos del hospital aplicaran el antídoto indicado. (Diario de campo del taller con aserradores de la comunidad, 2016)

Sin embargo, la atención de salud se ha ido restringiendo en la Base Naval. En palabras de uno de los líderes del cc, esto ha sido producto de la política del Ministerio de Defensa:

En el 2002-2003, la Armada comenzó a restringir eso que era la sanidad militar, y que nosotros teníamos que ser atendidos por la $\operatorname{ESE}^{25}$ que es en el

24 Para ampliar la información, véase: Fundación Ideas para la Paz (2013).

25 Empresa Social del Estado o red de servicios de salud de primer nivel. 
Distrito de Buenaventura [sic]. Eso nace ya, pues como una política, por algunos incidentes y porque hubo como mucha demanda. (Taller de línea de tiempo, La Plata, noviembre de 2016)

Para varios de los pobladores esto sucedió durante el primer gobierno de Álvaro Uribe (2002-2006) como respuesta a la seguridad de civiles y del personal militar. Como lo especifica el miembro de la Junta, la demanda por servicios de salud era bastante alta, aun así, decidieron no atender población civil, excepto si se trataba de un asunto «de vida o muerte». Desde ese entonces, la población debe viajar hasta Juanchaco y Buenaventura o buscar la ayuda de curanderos, que en esta región del Pacífico se están acabando. Aunque en Bahía Málaga hay varios mayores que tienen conocimientos de plantas medicinales para curar enfermedades, solo queda uno reconocido como curandero.

\section{Episodio 2: Disputas territoriales}

En este apartado se exponen las diversas disputas que ha librado la población negra de Bahía Málaga con actores académicos (relacionados con la investigación de fauna y flora terrestre y marina), de conflictos inter e intraétnicos, armados (legales e ilegales) y con el mismo Estado por la construcción de megaproyectos portuarios.

\section{Por la biodiversidad con Univalle}

A mediados de los años sesenta, la Universidad del Valle solicitó al Gobierno un territorio para adelantar investigaciones biológicas y ecológicas en el Pacífico vallecaucano. Ante esta petición, se concedieron 32000 hectáreas en condición de Reserva Natural Especial, con resolución de Incora 147 de 1967, establecida y aprobada mediante la Resolución del Ministerio de Agricultura 299 de octubre 4 de 1967 (Sánchez, 2011). En los años ochenta, varias personas de la comunidad trabajaron en conjunto con la Universidad en un proyecto de cría de pescado y camarón. 
Pero, a finales de los años noventa y principios del 2000, la Universidad del Valle reclamó que parte del territorio titulado a las comunidades negras le pertenecía para la investigación. Con este fin, adelantó un recurso de oposición frente a la titulación de tierras e inició una disputa con el Consejo Comunitario que duró aproximadamente tres años, hasta que el Instituto Colombiano de Desarrollo Rural (Incoder), organismo que sustituyó al Incora, se pronunció en favor del Consejo. Entonces, Univalle tuvo que negociar con la comunidad; así quedó registrado en un diario de campo:

En nuestra tercera salida hablamos con representantes del Consejo Comunitario y les preguntamos por lo sucedido con la Universidad del Valle. Uno de ellos mencionó que nunca estuvieron en contra de la investigación, al contrario, él estableció que eso les convenía. Él dijo que solo querían el reconocimiento de las tierras, a lo que se oponía la institución. Dice él: «la Universidad pudo seguir, pero bajo los acuerdos que nosotros les propusimos, nosotros como adquirientes de la titulación colectiva, como representantes de nuestro territorio». (Testimonio de un integrante del Consejo Comunitario de La Plata)

Después de este incidente, la relación entre el cc y la Universidad del Valle se ha transformado. A la fecha han adelantado varias investigaciones conjuntas que incluyen proyectos de caracterización (Orozco et al., 2008), ingeniería (Segura, 2006), generación de ingresos (Plaza, 2008), (re)conocimiento de la biodiversidad de la zona y preservación de especies endémicas de fauna y flora terrestre y marina (Viveros, 1998; Guzmán, 2003; Ávila, 2006; Ocampo, 2009; Castillo, 2009; Uribe Castañeda, 2013; Giraldo, 2016).

\section{Conflictos inter e intraétnicos}

Los conflictos por tierras y territorios entre diferentes grupos étnicos no han sido pocos en el Pacífico. Indígenas y comunidades negras y afrocolombianas se han enfrentado a colonos y organizaciones foráneas que han llegado a desarrollar actividades, legales e ilegales, de extracción 
de madera, de minería y de cultivo y procesamiento de drogas ilícitas, entre las más importantes ${ }^{26}$. En el caso particular de La Plata, los conflictos armados en el sur del Chocó y al sur de Buenaventura obligaron a varios pueblos indígenas a desplazarse hacia el norte y sur del Pacífico. Así sucedió con comunidades embera dóbida, embera chamí, embera katío, eperara siapidara, wounaan, awá y tule, algunas de ellas declaradas en situación de alto riesgo (Colombia, 2009; Moreno, 2007; Colombia, 2013).

También se han presentado conflictos entre comunidades indígenas y negras como sucedió cuando el cc de La Plata denunció que unos terrenos otorgados a los embera wounaan, como ampliación del resguardo El Papayo, correspondían con zonas de pesca, caza y siembra ancestral de las comunidades negras de la ensenada de El Bongo. Esto generó disgusto entre los embera y el consejo comunitario, razón por la cual el Incoder resolvió conceder una ampliación en el terreno del título colectivo del Consejo de La Plata para calmar los ánimos tras la petición de la revocatoria del título de los indígenas (Escobar, 2013). Después de esto, la relación ha sido muy buena y no se han presentado más inconvenientes por asuntos territoriales.

Así mismo, los conflictos entre comunidades y organizaciones negras, de carácter intraétnico, comprenden disputas internas como las que han librado por erradicar y transformar prácticas políticas y de liderazgo de tipo clientelista y de corrupción, que hacen parte de la cultura de partidos y organizaciones políticas en Colombia, casi desde el nacimiento del Estado-nación. Un ejemplo de estas pugnas se observa en el reciente revés jurídico vivido por Rosa Solís, reconocida líder afrocolombiana de Buenaventura. El Tribunal Administrativo de Cundinamarca ordenó revocar los títulos colectivos de Gamboa y La Caucana, ubicados en el Valle del Cauca, por considerar que su adjudicación fue irregular.

26 Parta ampliar los ejemplos de enfrentamientos y solicitudes de títulos, véase: Verdad Abierta (27 febrero de 2014) y El Espectador (2016). 
Según Molano (2017), Solís había construido allí un verdadero «emporio político y económico». La demanda de nulidad de la adjudicación fue interpuesta por el representante legal del Consejo Comunitario de La Plata de aquel entonces y líder de varios procesos de comunidades negras en el Pacífico.

\section{Con los actores armados ilegales}

De acuerdo con información testimonial y documental, La Plata no ha sido significativamente afectada por las acciones y enfrentamientos de actores armados legales e ilegales. Sin embargo, sus territorios y comunidades han estado expuestos a la presencia, la amenaza y los efectos colaterales producidos por las disputas territoriales de los actores armados en la región y especialmente en Buenaventura. La ubicación geográfica, las condiciones naturales de la Bahía, el tejido y cohesión social de sus comunidades y la ubicación de la Base Naval figuran como los asuntos centrales de esta situación privilegiada, reconocida tanto por los pobladores de La Plata como por otras comunidades e instituciones de la zona.

Agudelo (2001) sostiene que los grupos guerrilleros, primordialmente las Fuerzas Armadas Revolucionarias de Colombia (FARC), han hecho presencia en el Pacífico colombiano desde finales de los años setenta. La construcción de la Base Naval en los años noventa fortaleció la presencia de las fuerzas militares del Estado en la región y contrarrestó la expansión guerrillera, especialmente en los puertos de Tumaco, Guapi y Buenaventura. Sin embargo, a comienzos del presente siglo, la llegada del narcotráfico y de grupos paramilitares a la región se convierte en uno de los factores que desencadena la escalada de confrontaciones armadas y la violencia contra la población civil en la zona (CNMH, 2015 y 2018).

Entre los años 2005 y 2013, aumentaron no solo los Grupos Armados Ilegales (GAI) en estos territorios, sino también sus prácticas criminales y de terror, debido a las disputas por rutas de armas, contrabando y drogas ilícitas. En medio de este contexto, el Consejo Comunitario La Plata, 
Bahía Málaga, a través de las gestiones practicadas por sus líderes, se incluyó en el Registro Único de Víctimas a través de la Resolución $\mathrm{n}^{\circ}$ 2014-688280 del 21 de noviembre de 2014. De esta forma, se circunscribió en un proceso de atención y reparación integral para la comunidad, que se ha visto involucrada en hostigamientos, retenciones e incluso asesinato, en medio de la guerra sucia que se ha vivido en la región.

\section{Los puertos de aguas profundas}

Desde comienzos del siglo xx, instituciones del Estado colombiano ya consideraban la construcción de un puerto alterno de aguas profundas en el Pacífico, pues Buenaventura no reunía las condiciones necesarias para la llegada de barcos mucho más grandes. Entre 1917 y 1918 se hicieron los primeros estudios para construir un nuevo puerto a cargo del general Pablo Emilio Escobar en las bahías de Cupica, Solano, Tribugá y Málaga (Escobar, 1991).

Cabe recordar que, desde 1959, el Pacífico cuenta con la declaración de Zonas de Reserva Forestal por la expedición de la Ley 2, la cual jugó un papel importante como una de las primeras políticas de regulación de la economía forestal. Bajo una mirada más institucional, esta fue considerada una política de conservación de los bosques nativos del Pacífico colombiano, con el fin de

orientar los procesos de ordenación ambiental al interior de estas áreas, sirviendo como insumo planificador y orientador en materia ambiental para los diferentes sectores productivos del país, sin generar cambios en el uso del suelo, ni cambios que impliquen modificar la naturaleza misma de la Reserva Forestal. (Colombia, s. f., p. 1)

En el año 2005, se vuelve a proponer la construcción de un puerto en Bahía Málaga, con la presentación de la agenda «Valle Competitivo», que perseguía la integración del Valle del Cauca en los mercados asiáticos para fomentar el desarrollo económico en la región (Escobar, 2013). Se argumentaba que, el hecho de no contar con el puerto conllevaba un 
alto costo de oportunidad para Colombia y un retroceso en los esfuerzos por aumentar el comercio con las emergentes economías asiáticas y estadounidenses (Vieira, 2006).

Sin embargo, esta visión de desarrollo significaba para los malagueños no solo atentar contra su entorno natural y biodiverso, sino contra sus tradiciones culturales. Estos asuntos fortalecieron la participación en los Consejos Comunitarios de Bahía Málaga y la movilización social alrededor de la protección del territorio y la oposición a la construcción del puerto de aguas profundas (Notas del diario de campo, abril de 2016). Liderados por el CCP de La Plata, los CC establecieron alianzas con sectores académicos y ambientalistas e impulsaron una valoración de la riqueza biológica de la Bahía, basada en su diversidad de flora y fauna.

En este marco, se gesta una nueva colaboración del CCP de La Plata con el Instituto de investigaciones Marinas y Costeras (Invemar), la Universidad del Valle y el Instituto para la Investigación y la Preservación del Patrimonio Cultural y Natural del Valle del Cauca (Inciva). En el año 2006, se publicó el informe Biomálaga, con un diagnóstico de las condiciones ecológicas de Bahía Málaga y se instauraron parámetros para la conservación de los ecosistemas de la zona.

El estudio sirvió como prueba para que la Corporación Autónoma Regional del Valle del Cauca (Cvc) decidiera proteger una zona de la Bahía. En el año 2008, el Acuerdo 55 declaró el Parque Natural Regional La Sierpe, una extensión de 25178 hectáreas que incluyen zonas de bosque pluvial tropical y zonas bajas inundables. Además, con el Acuerdo 56, se creó un Distrito de Manejo Integrado para los recursos naturales renovables, que orientaba la gestión del área protegida, para conservar los sistemas marinos y costeros de Bahía Málaga.

Pero, en el año 2010, continuaba latente la posibilidad de construir el puerto de aguas profundas. Nuevamente los cc se organizaron y convocaron a masivas manifestaciones, que involucraron organizaciones sociales 
y activistas; así lograron la declaración del Parque Natural Nacional Uramba Bahía Málaga (figura 1), con Resolución 1501 de 2010. De esta manera, conquistaron de nuevo la derogación del proyecto del puerto y crearon «mecanismos de blindaje» para proteger sus territorios y culturas, que incluían proyectos productivos y de turismo ambiental y herramientas para preservar sus recursos de la explotación de agentes nacionales e internacionales de carácter público y privado. En ese sentido, esta lucha contra la construcción de un puerto de aguas profundas en Bahía Málaga también es una resistencia eco-etno-social y comunitaria por parte de la población que, con ayuda y buenas estrategias de visibilidad, consiguieron un resultado positivo frente a la protección del territorio.

A pesar de los beneficios mencionados, existen contradicciones relacionadas con la creación de los parques naturales para salvaguardar la Bahía, puesto que esta también ha tenido implicaciones negativas en la vida cotidiana de los malagueños. Por una parte, la existencia de los parques supone que estos territorios se han convertido en espacios públicos, con libre circulación y uso por parte de personas ajenas, lo que afecta la soberanía y autonomía de la comunidad; así mismo, estimula la colonización o explotación acelerada e indiscriminada de los bosques y demás recursos naturales de la Bahía (Serje, 2005; Programa de las Naciones Unidas para el Desarrollo, 2011). Por otra parte, las políticas de conservación se han hecho más fuertes e inflexibles, lo que perjudica tanto la sobrevivencia de las comunidades como su estigmatización y criminalización, sin considerar que fueron los mismos cuidados y el adecuado balance de los recursos naturales los que permitieron que les fueran otorgados los títulos de cuidado y protección de sus territorios.

\section{Organización para el desarrollo y la buena vida}

Salir adelante, sin afectar el entorno, sin contaminar y sin quebrantar los procesos naturales, sin desafiar a la luna, sin retar a la marea. Notas del diario de campo, noviembre de 2016. 


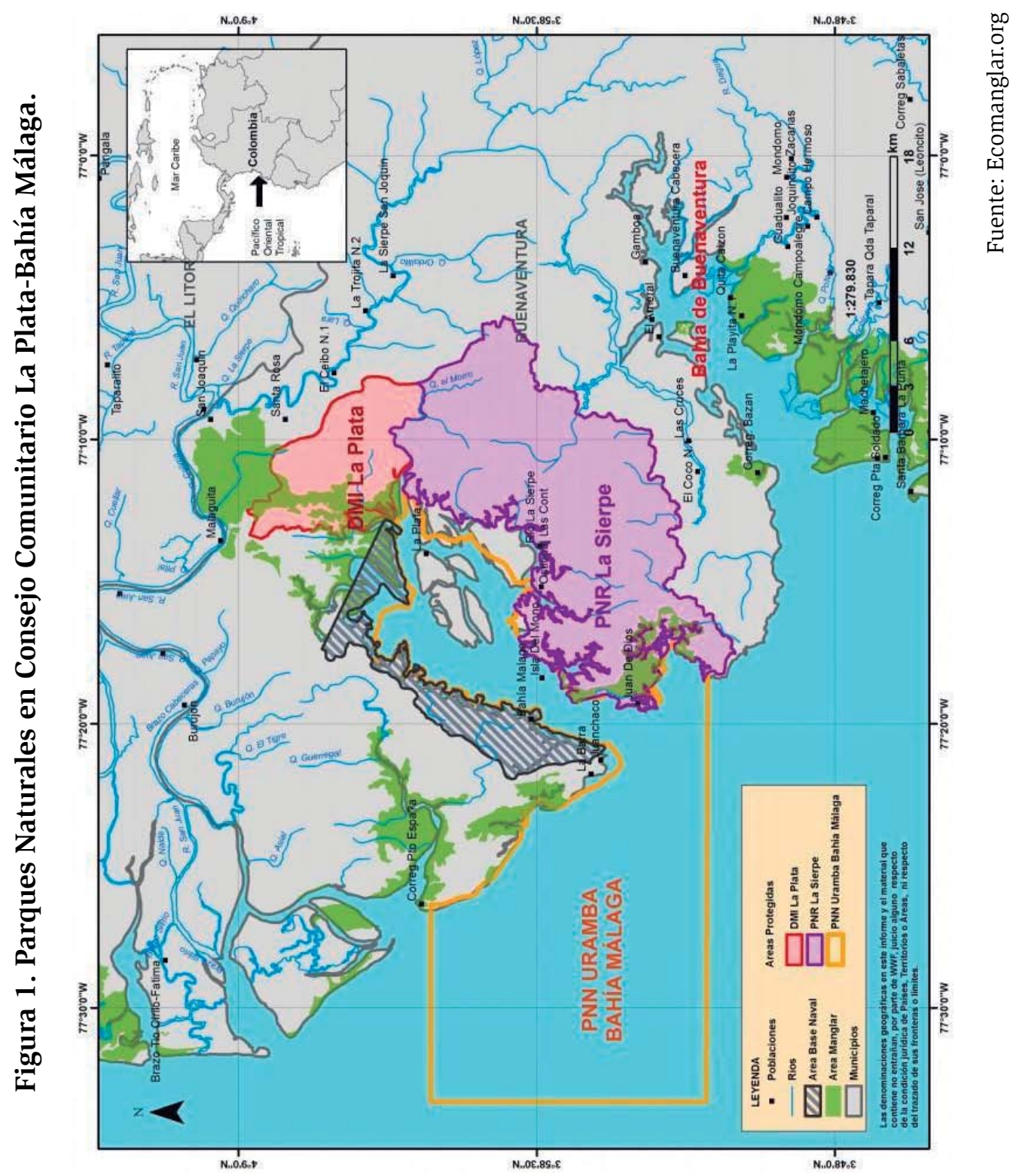


En los casi 20 años de existencia del Consejo Comunitario de La Plata, su población se ha reducido en un $50 \%{ }^{27}$, lo que, según la comunidad, se debe a la migración de sus miembros por tres razones principales: a)las dificultades que enfrentan por la reducción de alimentos y alternativas de trabajo y generación de ingresos, b) la falta de educación (en términos de cobertura, calidad y pertinencia étnico-territorial) y c) los problemas de salud, asociados con la inexistencia de sistemas que garanticen no solo el acceso y calidad de este derecho básico, sino la integración de conocimientos y prácticas tradicionales.

Las acciones organizativas del cc de los últimos años se han centrado en la búsqueda de alternativas internas y externas de permanencia y subsistencia en el territorio, y en la construcción de un bienestar que corresponda con sus características y aspiraciones étnicas. En este sentido, los proyectos económicos y las alternativas de generación de ingresos hacen parte de las prioridades de la comunidad, así como las iniciativas que buscan asegurar una educación pertinente y de calidad para los niños y jóvenes. Igualmente, ocupan un lugar primordial los proyectos de salud que puedan dar respuesta a los retos y problemáticas ambientales enfrentados, dadas las transformaciones económicas, culturales y tecnológicas de sus entornos locales y globales, a saber, el manejo del agua y las basuras, el impacto que producen los visitantes y el público que recorre y usa sus territorios o la implementación de espacios y rutas de salud que aseguren la atención primaria.

En razón a esto, las acciones del cc se han concentrado en interacciones con instituciones y organizaciones para la implementación de proyectos de desarrollo y de cooperación, que incluyen agentes estatales y privados del ámbito local, nacional y global. Sus acciones, de igual manera, han privilegiado la búsqueda de acuerdos políticos para el diseño y puesta en práctica de políticas públicas que aseguren las perspectivas,

27 Esta información es producto del censo practicado en 2017. 
saberes y planes de los malagueños, tensiones que valdría la pena conocer y analizar con profundidad.

Las interacciones y negociaciones del ccP de La Plata con las instituciones locales en temas de salud y educación son irregulares y poco efectivas; se enfrentan con la situación general del municipio, que muestra que en Buenaventura solo el $75,3 \%$ de la población tiene como máximo título educativo la secundaria y solo el $8,9 \%$ son profesionales. La ciudad tampoco cuenta siquiera con servicio público de salud de mediana complejidad y más de la tercera parte de la ciudad (50 mil personas) ha sido víctima del conflicto armado y las violencias; asimismo, los últimos cuatro alcaldes han sido vinculados con millonarios casos de corrupción, incluido el actual, por desfalcos en el campo de la salud ${ }^{28}$.

En el contexto presentado, destacan iniciativas eco-etno-sociales como Ecomanglar, proyecto enfocado en el turismo especializado en la ecología y el factor étnico de la zona, el cual brinda experiencias que combinan aprendizajes de la naturaleza y de la cultura de los malagueños. Esta no es solamente una alternativa para generar ingresos, sino también una oportunidad para fortalecer la autogestión local y mejorar la calidad de vida de la comunidad. El proyecto ha recibido apoyo de instituciones nacionales como la Universidad Nacional, con programas de formación e investigación, y de organizaciones internacionales como la Agencia de Estados Unidos para el Desarrollo Internacional (Usaid) y Naciones Unidas, que han apoyado iniciativas de construcción de infraestructura.

Otra iniciativa significativa en términos económicos, pero también políticos y ambientales para La Plata, y en general para el Pacífico colombiano, es la presencia del proyecto REDD + (Reducing Emissions from Deforestation and Forest Degradation), que busca reducir la deforestación y la degradación, conservar y manejar sosteniblemente los

28 Datos de Colombia (2018) y Unidad de Víctimas (2017). 
bosques y aumentar las reservas forestales de carbono (REDD + , S.F). El programa se negoció en 2012 y se han desarrollado acciones de capacitación y acuerdos de pesca artesanal y recolección de piangua, con el fin de mantener la sostenibilidad a largo plazo de ciertas especies. También se ha fortalecido el ecoturismo y la construcción de cabañas ecológicas, que hacen parte de los proyectos de infraestructura mencionados anteriormente.

No obstante, la presencia y los acuerdos con REDD + son muy complejos y delicados para el Consejo, no solo porque este programa los pone a interactuar y negociar con agentes internacionales y globales, o a hacer parte de la estructura y negocios capitalistas, sino porque plantea discusiones y desarrollo de proyectos que pueden afectar seriamente su supervivencia ambiental, cultural, de autogobierno y soberanía y sus relaciones con instituciones y organizaciones de carácter local y regional. Uno de los pobladores expone así las sensibles relaciones con el programa: «tenemos que conocer el mercado, los bonos de carbono, y, si vamos a dejar de utilizar los bosques, tenemos que conocer las reglas de juego, cómo funciona, porque las comunidades vivimos de eso».

También ha sido importante el desarrollo de la infraestructura de telefonía de empresas privadas en la zona y los proyectos de acceso y uso de Tecnologías de Comunicación e Información (TIC). Como parte de un programa del Ministerio de TIC, desde hace unos años se instaló un punto Vive Digital que, a pesar de los problemas técnicos de conexión y de continuidad por asuntos de orden administrativo, ha permitido una mayor conexión y comunicación de los jóvenes con el mundo global. Esto ha favorecido el diálogo de los pobladores con las instituciones y organizaciones con las que desarrolla proyectos de diferente tipo; al mismo tiempo, ha permitido una mayor difusión y desarrollo del ecoturismo, principalmente en otros países europeos y de América Latina ${ }^{29}$.

29 Con apoyo de la Universidad de los Andes, que promovió y acompañó la creación de páginas de promoción Eco-Manglar en internet. 
De igual manera, representa un beneficio para la interacción de las personas que han migrado temporal o permanentemente y el fortalecimiento de actividades informativas y educativas, principalmente de niños y jóvenes, para la interlocución con diversos actores sociales; incluso, ha contribuido a mejorar los envíos de dinero y recursos por parte de la gente de la comunidad y de fuera de esta.

\section{Discusión y conclusiones: resistencias, territorios y Estado}

Los episodios que hemos propuesto para el caso de La Plata nos permiten deducir tres asuntos centrales: a) sus organizaciones y movilizaciones han respondido a las ausencias-presencias del Estado-nación de Colombia con estrategias de movilización social y resistencia, pero también de adaptación, negociación y apropiación de normas y pautas políticas, económicas y culturales; b) sus reclamos políticos y sociales corresponden con acciones de largo aliento que han buscado mantener y proteger el territorio y sus comunidades, así como la construcción de una noción de desarrollo entendida como una vida tranquila, con solidaridad y apoyo comunitario, con preservación y uso de valores y costumbres tradicionales, con buenos alimentos y salud, y con posibilidades de formación y educación tanto étnica como convencional; c) recurren a formas alternativas de organización y a repertorios que combinan las redes de solidaridad y sus tradiciones de justicia con prácticas tradicionales de acción política como el clientelismo, la participación en la producción de políticas públicas y el lobby.

Hoffman (2007) afirma que la región Pacífica experimentó una integración tardía a la Nación. La Plata muestra que esta comunidad ha hecho parte de las formas precarias y diferenciales del desarrollo del Estado-nación. En diferentes momentos y con agentes diversos, las comunidades, organizaciones y movimientos se integraron o hicieron parte de procesos locales, nacionales e internacionales, que van desde la participación en Juntas de Acción Comunal o la institucionalización de un corregimiento o su involucramiento en las dinámicas clientelistas 
de los partidos tradicionales o la negociación de la presencia de empresas privadas o de fuerzas armadas en sus territorios.

Estos procesos también incluyen las movilizaciones y protestas que han confrontado a las instituciones de orden regional y local. Ejemplo de esto son los conflictos que han tenido con la CVC y la Universidad del Valle en relación con la propiedad y el uso de la tierra y los recursos de la región o con el gobierno nacional y los entes privados, que en diferentes momentos han propuesto (y siguen proponiendo) megaproyectos como el puerto de aguas profundas en la Bahía o la instalación de infraestructuras para el transporte y exportación de petróleo y sus derivados. A lo anterior se suman las interacciones del CC con el Estado nacional colombiano, que pasan por las disputas por la producción o ejecución de leyes o políticas, como ha sucedido con los desarrollos de la Ley 70, o sus relaciones con otras organizaciones y países (como Estados Unidos), por la vía de proyectos económicos, culturales o políticos o por los negocios con bonos de carbono.

A estas instituciones, organismos y colectivos no solo se les reclaman bienes materiales, simbólicos e institucionales —incluso de conocimiento y espirituales-, sino que también se negocian y se acuerdan acciones que tienen que ver con estos bienes. Es decir, no existe un distanciamiento ni un desconocimiento total del Estado-nación o de organizaciones como los partidos políticos, sino que estos son mantenidos como referentes de sus luchas y acciones; a su vez, se acude a ellos como aliados o como parte de sus redes clientelares o para la negociación de políticas públicas o la participación de programas y proyectos sociales.

De acuerdo con los testimonios de líderes de la comunidad, el día a día de La Plata se basa en la resistencia, en la lucha, en la protección firme de su territorio, que para ellos es su vida como lo planteó un habitante de Bahía Málaga: «nuestra lucha es un todo o nada». La resistencia cotidiana que ha vivido la comunidad es producto también de las concepciones y prácticas de un «desarrollo» que apunta a un equilibrio 
entre el ser y el permanecer e insiste en procesos que contribuyan a un crecimiento propio y sostenible, a la búsqueda de armonía entre comunidad y naturaleza (por ejemplo, mediante el control de los procesos de colonización y la presencia de foráneos y turistas) y al consumo moderado (por ejemplo, a través de la recuperación de prácticas tradicionales de producción agrícola y el desarrollo de alternativas y reglas de pesca y recolección de moluscos que no agoten los ecosistemas de la Bahía). Estas prácticas se juegan en el diario vivir, más que como respuestas a políticas o parámetros externos -que corresponden, parcialmente, con el argumento de territorialización de las luchas que propone Zibechi (2012) - , como una resistencia cotidiana eco-etno-social, cultural y política.

Las trayectorias de movilización de La Plata también corresponden con estructuras de poder muy concentradas y con una desigualdad crónica. De igual forma, muestran que las movilizaciones de la comunidad de La Plata son motivadas por la incapacidad o por la falta de decisión de las instituciones nacionales y locales, que no han logrado tramitar conflictos y demandas de largo aliento. A eso se debe su desafío a los Estados-nación, ya que proponen otras formas y normas culturales y la producción de otras instituciones comunitarias, locales y regionales. Lo anterior se evidencia en sus pugnas con otras comunidades y organizaciones étnicas, en los contenidos de sus reglamentos internos, en las estructuras y procedimientos descentralizados de toma de decisiones, en el respeto y cuidado de los niños, jóvenes y viejos y en la importancia de la espiritualidad y los valores culturales.

Con este objetivo, la comunidad de La Plata adaptó y adoptó diferentes formas de organización y de interacción. Algunas de estas son más parecidas a las de las instituciones del Estado-nación, otras a repertorios más tradicionales de movilización o a las prácticas de lobby y negociación de agencias internacionales o a la participación en redes de poder local, que les permitieron la construcción del salón comunal, de la escuela, del centro de salud o del quiosco de TIC. Esto no 
desconoce otras formas de organización como los consejos y consultas a los mayores, que tradicionalmente se hacen en la comunidad, o las redes organizativas de mujeres y jóvenes, de pescadores y de piangüeras, que se han creado con valores de solidaridad y preservación étnica, o la integración de los cantos, la fiesta o los rituales fúnebres como espacios de fortalecimiento comunitario y de construcción y reconstrucción de relaciones de poder ${ }^{30}$.

Sus formas de resistencia también han rechazado el uso de las violencias, que por demás son parte de las estrategias implementadas históricamente por entes estatales y de grupos armados ilegales, que también incluyen la marginación y la discriminación de grupos étnicos y culturales. Los recuerdos y memorias son permanentemente utilizados para narrar a los niños, jóvenes y a la comunidad relatos sobre su historia y sus movilizaciones.

En conclusión, los episodios identificados en este estudio, más que a la búsqueda de unos órdenes o concepciones diferentes o exclusivas (o, en algunos casos, esencialistas), propenden por unas nociones y prácticas de las resistencias que articulan asuntos como: a) la permanencia de las comunidades y sus descendientes en las tierras que fueron habitadas por ellos desde hace más de un siglo; b) el cuidado de los territorios que han configurado y reconfigurado — que incluyen los integrantes de sus comunidades y los espacios geográficos, naturales y sociales que habitan-, el cual involucra formas organizativas de poder y de solidaridad comunitaria y ambiental; c) las prácticas y creencias

30 Esto se puede percibir, por ejemplo, en eventos como el velorio de Miramar, en el que miembros de la Junta del Consejo hicieron el recorrido hasta la última casa saludando familiares y amigos con cariño y amabilidad. En su recorrido, recibían sugerencias, críticas y solicitudes de proyectos, obras y normas para desarrollar y aplicar. También recibían algunos informes de los representantes de las veredas, o aprovechaban para conversar sobre asuntos urgentes o que requerían de la atención conjunta en los próximos días o semanas (Notas del diario de campo, 2016). 
culturales multiétnicas $^{31}$ (negras, afro, campesinas), relacionadas con la historia, el lenguaje, la espiritualidad, la comida, la sobrevivencia y la producción.

Los episodios también ponen en evidencia unas nociones de territorios más flexibles, con coberturas más amplias y dinámicas, que se extienden con los ires y venires de la movilidad humana de las comunidades entre muy diferentes zonas rurales y urbanas, y de las mismas movilizaciones sociales del Consejo Comunitario. Estas nociones y prácticas involucran, además de la materialidad de los territorios, otras dimensiones culturales que brindan identidades y límites de control simbólico, así como de carácter político, de apropiación y ordenamiento del espacio y de los individuos que lo habitan. Así mismo, conllevan el agenciamiento de individuos y colectividades que desterritorializan y reterritorializan permanentemente sus territorios (Herner, 2009; Escobar, 2008).

Aunque los seres humanos y naturales del territorio de La Plata han disminuido significativamente en las últimas dos décadas, como lo evidencia el Censo de 2017, las prácticas y cosmovisiones tradicionales de pesca, el uso de los bosques, las medicinas y los curanderos, la música, la comida, la educación y la organización también se han transformado velozmente en las últimas tres décadas, debido a las nuevas interacciones sociales con agentes e instituciones diversos y a la integración de varios tipos de tecnologías. Sin embargo, las columnas vertebrales de esta comunidad - los pescadores, los madereros, las nuevas generaciones de líderes, los grupos de mujeres y jóvenes, los prestadores de servicios eco-etno-turísticos, en general- siguen apostando por la defensa y sobrevivencia de una comunidad con particularidades, necesidades y sueños diferentes, que les brindan referentes de identidad y de sentido para vida. Desde allí contribuyen al enriquecimiento de la conformación del Estado y de la nación, cuando estos tienen la

31 Para ampliar la información, véase Alund (2003). 
capacidad de escuchar y actuar consecuentemente con estas riquezas más híbridas, móviles y cambiantes que, de paso, desafían nuestras propias nociones y prácticas de resistencia.

A pesar de lo expuesto, los procedimientos, la estructura y las prácticas de organización y movilización en La Plata requieren todavía de un mayor empoderamiento, formación y visibilidad de las mujeres y los jóvenes, quienes deben mostrarse más activos e importantes en los espacios y momentos de toma de decisiones y acciones políticas. De la misma manera, las tecnologías de comunicación e información - a las que desde hace tiempo tienen acceso- que han empezado a utilizar para actividades educativas y económicas, podrían favorecer más sus expresiones socioculturales y políticas y sus vínculos con organizaciones y movimientos nacionales y globales; si el uso de estas se compara con el que le dan otros movimientos nacionales e internacionales, resulta escaso y débil. Estos asuntos, sumados a miradas más profundas sobre las relaciones entre los procesos de organización y movilización social y la co-construcción del Estado-nación, representan algunos de los principales ejes para estudios futuros.

\section{Referencias}

Alund, Aleksandra (2003). Etnicity, social subordination and cultural resistance. En: Grete Brochmann (ed.), Multicultural challenge. Comparative social research, (22), 245-261.

Archila, Mauricio y García, Martha (2015). Violencia y memoria indígena en Cauca y La Guajira. Memoria 19(38), 107-118. DoI http://dx.doi. org/10.11144/Javeriana.mys19-38.vmic

Armada Nacional (2011). Base Naval ARC «Málaga», un propósito nacional. Feriva S. A.

Arocha, Jaime (1998). La inclusión de los afrocolombianos, ¿meta inalcanzable? En: Los afrocolombianos. Geografía humana de Colombia, tomo VI, 333-95. Bogotá: Instituto Colombiano de Cultura Hispánica. 
Asher, Kiran (2016). Negro y verde: etnicidad, economía y ecología en los movimientos negros del Pacífico colombiano. Cali: Icanh e Icesi.

Ávila Jiménez, Isabel (2006). Patrones en la conducta superficial diurna de la ballena jorobada (Megaptera novaeangliae) en la bahía de Málaga y zonas aledañas, Pacífico colombiano. Tesis de maestría en Biología, Facultad de Ciencias Naturales y Exactas. Santiago de Cali: Universidad del Valle.

Barrera, Víctor (2016). Algunas claves analíticas. Tendencias de la movilización social en municipios críticos para el posconflicto. Documentos Ocasionales $n .^{\circ}$ 80. Cinep, Programa por la Paz.

Barón, Luis (2013). The power of associations. Social media and social movements: Facebook in the interactions of social movement organizations. Washington: University of Washington.

Calderón, Fernando (2012). La protesta social en América Latina. En: F. Calderón (coord.), Cuaderno de Prospectiva Política 1. Buenos Aires: Siglo XXI Editores S. A.

Callon, Michell (1987). Society in the making: The study of technology as a tool for sociological analysis. En: E. Bijker, T. P. Hughes y T. J. Pinch (eds.), The social construction of technological systems: new directions in the sociology and history of technology, 83-103. New York: MIT Press.

Cardona, César Alejandro (2017). Proceso organizativo de las comunidades negras rurales de Antioquia. Ancestralidad, etnicidad y política pública afroantioqueña. Estudios Políticos, 50, 180-202. Universidad de Antioquia. DoI: 10.17533/udea.espo.n50a10

Castellanos Galindo, Gustavo (2003). Interacciones tróficas y espaciales de un ensamble de peces de charcos intermareales en un acantilado rocoso tropical, bahía Málaga-Pacífico colombiano. Tesis de Biología, Facultad de Ciencias Naturales y Exactas. Santiago de Cali: Universidad del Valle.

Castillo Cutiva, Leslie Anais (2009). Diversidad genética de una población insular de la tortuga hicotea blanca (Rhinoclemmys nasuta) en la Isla Palma, Bahía Málaga, utilizando microsatélites. Tesis de Maestría en Ciencias-Biología, Facultad de Ciencias Naturales y Exactas. Santiago de Cali: Universidad del Valle. 
Centro Nacional de Memoria Histórica (2015). Estudio sobre los orígenes del conflicto social armado, razones de su persistencia y sus efectos más profundos en la sociedad colombiana. Bogotá: CNMH.

Centro Nacional de Memoria Histórica (2015). Buenaventura: un puerto sin comunidad. Bogotá, Colombia: CNMH.

Cinep/Programa por la Paz (2016). Tendencias de la movilización social en municipios críticos para el posconflicto. Documentos Ocasionales 80. Bogotá: Cinep y Programa por la Paz.

Colombia. Ministerio de Medio Ambiente y Desarrollo (s. f.). Reservas Forestales establecidas por la Ley $2^{a}$ de 1959. Recuperado de: https://www.minambiente.gov.co/images/BosquesBiodiversidadyServiciosEcosistemicos/ pdf/reservas_forestales/reservas_forestales_ley_2da_1959.pdf

Colombia. Ley 2 de 16 de diciembre de 1959.

Colombia. Ley 70 de 27 de agosto de 1993.

Colombia. Decreto 1745 de 1995.

Colombia. Consejo Comunitario de la Ensenada de Málaga (2005). Código de Régimen interno de la comunidad negra de la ensenada de Málaga y su territorio Colectivo, 1, 39.

Colombia. Resolución 1501 de 4 de agosto de 2010. Ministerio de Ambiente, Vivienda y Desarrollo Territorial. Por medio de la cual se declara, reserva, delimita y alindera el Parque Nacional Natural Uramba Bahía Málaga.

Colombia (2010). Plan Nacional de Desarrollo. Prosperidad para todos. República de Colombia.

Colombia. Ministerio del Interior y Orewa (2013). Plan de salvaguarda pueblo embera. Documento unificado planes regionales. Recuperado de: https:// siic.mininterior.gov.co/sites/default/files/pueblos_embera_chami_katio_ dobida_eperara_siapidara_-_diagnostico_unificado.pdf

Colombia. Defensoría del Pueblo de Colombia (2016). Problemática humanitaria en la región pacífica colombiana. Bogotá, D. C.

Colombia. Alcaldía de Buenaventura (2018). Informe pre-diagnóstico Buenaventura, РОт 2018-2030. Cali: Club de Ejecutivos. 
Corporación Autónoma Regional del Valle del Cauca. Acuerdo 55 de 14 de agosto de 2008. Por el cual se declara el Parque Natural Regional de La Sierpe ubicado en Bahía Málaga, municipio de Buenaventura, y se adoptan otras determinaciones.

Corporación Autónoma Regional del Valle del Cauca. Acuerdo 56 de 18 de agosto de 2008. Por el cual se declara un distrito de manejo integrado de los recursos naturales renovables en el territorio colectivo del Consejo Comunitario de la Comunidad Negra de La Plata, Bahía Málaga, municipio de Buenaventura, y se adoptan otras determinaciones.

De la Torre, Lucía Mercedes (2002). Historia de la Asociación Campesina Integral del Atrato (ACIA). Recuperado de: https://www.rds.org.co/aa/img_ upload/.../acia.pdf

Della Porta, Donatella y Diani, Mario (2006). Social movement: an introduction. Oxford: Malden Mass Blackwell.

Domínguez, Marta I. (2017). Territorios colectivos: proceso de formación del Estado en el Pacífico colombiano (1993-2009). Medellín: Universidad de Antioquia y Fondo Editorial FCSH.

El Espectador (2016). «Tumaco: voces de un conflicto ajeno». Recuperado de: http://colombia2020.elespectador.com/territorio/tumaco-voces-de-unconflicto-ajeno

El País (29 de enero de 2018). "Comercio exterior tuvo un repunte por Buenaventura en 2017». Recuperado de: https://www.elpais.com.co/economia/ comercio-exterior-tuvo-un-repunte-por-buenaventura-en-2017.html

Escobar, Arturo y Álvarez, Sonia (1992). The Making of social movements in Latin America: identity, strategy, and democracy. Oxford: Westview Press.

Escobar, Arturo (2008). Territorios de diferencia: Lugar, movimientos, vida, redes. Bogotá: Envión Editores.

Escobar García, Natalia (2013). Territorialidades en disputa: caso Bahía Málaga. Tesis de antropología, Facultad de Ciencias Sociales, Universidad Icesi, Santiago de Cali.

Escobar, Paulo (1921). Bahías de Málaga y Buenaventura: La costa colombiana del Pacífico 1918-1920. Bogotá: Editorial Nacional. 
Fundación Ideas para la Paz (2013). La crisis de Buenaventura la vive todo el Pacífico. Informe, noviembre de 2013. Recuperado de: http://cdn.ideaspaz. org/media/website/document/538795ac750bc.pdf

Fortunati, Leopoldina, Pertierra, Raúl y Vincent, Jane (2013). Migration, diaspora, and information technology in global societies. New York: Routledge.

García, Clara Inés, Guzmán, Álvaro, Aramburo, Clara Inés, Rodríguez, Alba Nubia y Domínguez, Juan Camilo (2014). Órdenes locales y conflicto armado. Una metodología comparada. Análisis Político 81(27), 3-18.

Giraldo Vaca, Juan Sebastián (2016). Importancia de los manglares como fuentes de productividad primaria para moluscos abundantes en Bahía Málaga. Tesis de Biología, Facultad de Ciencias Naturales y Exactas. Santiago de Cali: Universidad del Valle.

Grueso, Libia, Rosero, Carlos y Escobar, Arturo (1997). El proceso organizativo de comunidades negras en Colombia. Ecología Política, (14), 47-64.

Guzmán González, Pablo Andrés (2003). Crecimiento, madurez sexual y dimorfismo sexual de Littoraria zebra y L. Variegata (Mollusca: Mesogastropoda, Littorinidae) en un manglar de Bahía Málaga, Pacífico colombiano. Tesis de Biología, Facultad de Ciencias Naturales y Exactas. Santiago de Cali: Universidad del Valle.

Herner, María (2009). Territorio, desterritorialización y reterritorialización: un abordaje teórico desde la perspectiva de Deleuze y Guattari. Revista Huellas, 13,158-171.

Hoffmann, Odile (2003). Espacios y movilidad de la gente negra en el Pacífico sur colombiano: hacia la construcción de una sociedad regional. Revista de Estudios Afrobrasileras 25(1), 43-74.

Hoffmann, Odile (2007). Comunidades negras en el Pacífico colombiano. Innovaciones y dinámicas étnicas. Quito: Instituto de Investigación para el Desarrollo y el Instituto Francés de Estudios Andinos, Abya-Yala.

Jiménez, Nayibe y Delgado, Wilson (2008). La política pública de privatización del sector portuario y su impacto en la organización del trabajo en el Puerto de Buenaventura. Revista Pensamiento y Gestión, (25), 178-213.

Kafarov, Viatcheslav, Ojeda, Karina y Sánchez, Eduardo (2006). Situación y perspectiva de biocombustibles en Colombia. Anais do 6. Encontro de Energia no Meio Rural. Campinas Brasil. 
Leal, Claudia y Restrepo, Eduardo (1994). Unos bosques sembrados de aserríos: historia de la extracción maderera en el Pacífico colombiano. Colombia: Editorial Universidad de Antioquia.

Loaiza Naranjo, Jhonatan (2005). Aspectos ecológicos de la tortuga hicotea blanca (Rhinoclemmys nasuta boulenger, 1902) en Isla Palma, Bahía Málaga, Pacífico colombiano. Tesis de Biología con mención en Ecología, Facultad de Ciencias Naturales y Exactas. Santiago de Cali: Universidad del Valle.

Molano, Alfredo (2017). «El fallo que le quitó el poder a Rosa Solís». El Espectador. Recuperado de: https://www.elespectador.com/noticias/politica/elfallo-que-le-quito-el-poder-rosa-solis-articulo-686611

Moreno, Camila (2007). Desplazamiento interno forzado de indígenas en Colombia. Migraciones indígenas en las Américas, 141-154. San José de Costa Rica: Instituto Interamericano de Derechos Humanos.

Ó Loingsigh, Gearóid (2013). La reconquista del Pacífico: invasión, inversión, impunidad. Bogotá: Proceso de Comunidades Negras (PCN), Coordinador Nacional Agrario (CNA).

Ocampo Rojas, María Alejandra (2009). Diversidad de estadios de vida vulnerable de invertebrados marinos y heterogeneidad de hábitats en ambientes rocosos intermareales en Bahía Málaga, Pacífico colombiano. Tesis de Biología, Facultad de Ciencias Naturales y Exactas. Santiago de Cali: Universidad del Valle.

Orozco Cañas, Cecilia, Salcedo Hurtado, Elkin, Buitrago Bermúdez, Óscar y Martínez Toro, Pedro (2008). Caracterización espacial y funcional de Bahía Málaga. Colombia: Programa Editorial Universidad del Valle.

Oslender, Ulrich (1999). Espacio e identidad en el Pacífico colombiano. En: Eduardo Restrepo y Juana Camacho (eds.), De montes, ríos y ciudades: territorios e identidades de la gente negra en Colombia, 25-48. Colombia: Fundación Natura, Ecofondo e ICAN.

Plaza Salamanca, Carlos Alberto (2008). Evaluación del crecimiento y sobrevivencia de alevinos de pargo lunarejo (Lutjanus guttatus) (Steindachner, 1869), utilizando dos sistemas de cultivo: cerramientos naturales y jaulas flotantes en la zona de Bahía de Málaga, Pacífico colombiano. Tesis de Biología Marina, Facultad de Ciencias Naturales y Exactas. Buenaventura: Universidad del Valle. Sede Pacífico. 
Potes, Julio, Moreno, Stefany y Collazos, Jaime (2013). Composición de la economía de la región Suroccidente de Colombia. Banco de la República-Economía Regional.

Programa de las Naciones Unidas para el Desarrollo (PNUD) (2011). Afrocolombianos. Sus territorios y condiciones de vida. Bogotá: Programa de las Naciones Unidas para el Desarrollo.

REDD + (s. f.). Finanzas de carbono: plataforma sobre financiamiento climático para Latinoamérica y el Caribe. Recuperado de: http://finanzascarbono. org/

Restrepo, Eduardo (1999). Territorios e identidades híbridas. En: Eduardo Restrepo y Juana Camacho (eds.), De montes, ríos y ciudades: territorios e identidades de la gente negra en Colombia, 221-244. Colombia: Fundación Natura, Ecofondo e ICAN.

Restrepo, Eduardo (2001). Imaginando comunidad negra: etnografía de la etnización de las poblaciones negras en el Pacífico sur colombiano. En: Mauricio Pardo (ed.), Acción colectiva estado y etnicidad en el Pacífico colombiano, 41-70. Bogotá: Instituto Colombiano de Antropología.

Ruggiero, Vincenzo y Montagna, Nicola (2008). Social movements: a reader. New York: Routledge.

Said, Edward (2000). Invention, Memory and Place. Critical Inquiry, 26(2), (winter, 2000), 175-192. The University of Chicago Press.

Sassen, Saskia (2000). Territory and territoriality in the Global Economy. En: International Sociology, 15(2), 372-393. SAGE London: Thousand Oaks, CA and New Delhi.

Sánchez, Leopoldo (2011). Bahía Málaga 1910-2010: Cien años de confusión y olvido. Primera Edición. Cali: Universidad Libre Seccional Cali.

Segura Sogamoso, Juan Ricardo (2006). Sistema de información geográfica como herramienta para la valoración de la biodiversidad marina y costera de Bahía Málaga (Valle del Cauca, Pacífico colombiano). Tesis de Ingeniería Topográfica, Facultad de Ingeniería. Santiago de Cali: Universidad del Valle.

Serje, Margarita (2005). El revés de la nación. Territorios salvajes, fronteras y tierras de nadie. Bogotá: Universidad de los Andes.

Serje, Margarita (2012). El mito de la ausencia del Estado: la incorporación económica de las «zonas de frontera» en Colombia. Cahiers des Amériques Latines, 71, 95-117. 
Unidad de Víctimas (2017). Información de miembros Comité del Paro de 2017.

Uribe Castañeda, Natalia (2013). Vulnerabilidad ambiental y estrategias de conservación en el Parque Nacional Natural Uramba Bahía Málaga. Tesis de Biología, Facultad de Ciencias Naturales y Exactas. Santiago de Cali: Universidad del Valle.

Verdad Abierta (27 de febrero de 2014). Los afros del Cauca quieren sus tierras. Recuperado de: https://verdadabierta.com/los-afros-del-cauca-quieren-sutierra/

Vieira, Constanza (2006). Colombia: la bahía de las palabras. Recuperado de: http://www.ipsnoticias.net/2006/11/colombia-la-bahia-de-las-palabras/

Villa, Miguel (1996). Una nota acerca del Proyecto de Investigación sobre Migración Internacional en Latinoamérica (Imila). Programa Interinstitucional de Avaliação e Acompanhamento das Migrações Internacionais (2), 109-124.

Viveros Rodríguez, Eduardo (1998). Juveniles de moluscos marinos de Bahía Málaga: dinámica espacio-temporal. Tesis de Biología Marina, Facultad de Ciencias Naturales y Exactas, Universidad del Valle, Sede Pacífico, Buenaventura.

Walsh, Catherine, León, Edinzon y Restrepo, Eduardo (2005). Movimientos sociales afro y políticas de identidad en Ecuador y Colombia. En: Estudios de la diáspora Afro-Andina. Construcción de identidades afros en Ecuador y Colombia: procesos sociales, político y epistémicos, 209-253. Bogotá: La Imprenta Editores.

Wade, Peter (1993). El movimiento negro en Colombia. América Negra, (5), 173-191.

Zibechi, Raúl (2012). Territories in resistance: A cartography of Latin American social movements. Edimburgo: AK Press.

Zuluaga, Francisco y Romero, Mario (2007). Sociedad, cultura y resistencia negra en Colombia y Ecuador. Cali: Editorial Universidad del Valle.

\section{Autos}

Colombia (2009). Auto 004 de 2009. M. P. Manuel José Cepeda. 